\title{
EVALUATION OF THE EFFECT OF SUFENTANIL AND LIGNOCAINE COMBINATION IN PATIENTS UNDERGOING PERIANAL SURGERIES UNDER SPINAL ANAESTHESIA
}

\author{
Kiran Madhala1, Sridhar I2, Mabu Shareef Shaik3, Naveen Kumar $G^{4}$ \\ ${ }^{1}$ Assistant Professor, Department of Anaesthesia, Government Medical College, Nizamabad. \\ ${ }^{2}$ Assistant Professor, Department of Pharmacology, Government Medical College, Nizamabad. \\ ${ }^{3}$ Assistant Professor, Department of Pharmacology, Rajiv Gandhi Institute of Medical Sciences, Kadapa. \\ ${ }^{4}$ Registrar, Department of Anaesthesia, Kamineni Hospital, Hyderabad.
}

ABSTRACT
CONTEXT
Spinal anaesthesia with hyperbaric lignocaine has the limitation of relatively shorter duration of action, which means that early
analgesic intervention is needed in the postoperative period. Intrathecal opioid administration has a promising role in fulfilling this
objective. Sufentanil, the congener of fentanyl is 1000 more times potent than morphine is a newer addition to the armoury of
modern day anaesthesiologists.

\section{AIMS}

To compare the efficacy of sufentanil and lignocaine combination with lignocaine alone to reduce postoperative pain in patients undergoing perianal under spinal anaesthesia.

\section{SETTINGS AND DESIGN}

A prospective randomized single blinded study conducted after obtaining written informed consent, 100 patients aged above 18 years belonging to ASA Grade I and II scheduled to undergo perianal surgeries under spinal anaesthesia were enrolled in the study.

\section{METHODS AND MATERIAL}

The study population was divided into two groups of 50 each to receive the following treatments: $5 \%$ hyperbaric lignocaine 50 $\mathrm{mg}$ and $5 \%$ hyperbaric lignocaine $50 \mathrm{mg}$ with sufentanil $10 \mu \mathrm{g}$. All the drugs were administered intrathecally. All the patients were explained about the Visual Analog Scale (VAS) and standardized perioperative and anaesthetic procedures were followed.

\section{STATISTICAL ANALYSIS}

All data analysis was completed using SPSS software. Data were expressed as mean \pm SD. Quantitative data was analysed using unpaired ' $t$ ' test. Side effects were compared by Chi-square test. $\mathrm{P}<0.05$ was considered as statistically significant.

\section{RESULTS}

There was no variation with regard to the onset of sensory and motor blockade between the two groups. Significant increase in duration of complete and effective analgesia was observed in sufentanil group and the time for first dose of analgesic postoperatively was also significantly delayed. Pruritus was the most common side effect noted in sufentanil group.

\section{CONCLUSION}

Sufentanil potentiates lignocaine anaesthesia by increasing the duration and quality of analgesia and also decreases the ambulation time with minimal side effects.

\section{KEYWORDS}

Sufentanil, Lignocaine, Postoperative Analgesia.

HOW TO CITE THIS ARTICLE: Madhala K, Sridhar I, Shaik MS, et al. Evaluation of the effect of sufentanil and lignocaine combination in patients undergoing perianal surgeries under spinal anaesthesia. J. Evolution Med. Dent. Sci. 2016;5(31):1618-1621,

DOI: $10.14260 /$ jemds/2016/381

\section{INTRODUCTION}

The greatest gift god has given to mankind is not in happiness, but in relief of pain. In this pursuit many attempts have been made particularly to alleviate pain during and after surgery. Spinal anaesthesia introduced by Karl August bier in 1898 is one of the most popular techniques for both elective and emergency surgical procedures. ${ }^{1}$

Financial or Other, Competing Interest: None.

Submission 28-02-2016, Peer Review 24-03-2016,

Acceptance 29-03-2016, Published 16-04-2016.

Corresponding Author:

Mabu Shareef Shaik,

Assistant Professor,

Department of Pharmacology,

Rajiv Gandhi Institute of Medical Sciences,

Kadapa-516002.

E-mail: drsharifshaik@gmail.com

DOI: $10.14260 /$ jemds $/ 2016 / 381$
It is easy to perform with rapid onset of action, minimal drug cost, relatively less side effects and rapid patient turnover. The disadvantage with spinal anaesthesia using hyperbaric lignocaine is relatively shorter duration of action, which means that early analgesic intervention is needed in the postoperative period. Another disadvantage although infrequent is intraoperative nausea, particularly during manipulation of the peritoneum.

In the context of augmentation strategies, intrathecal opioid administration is a significant advancement in pain management. Studies have shown that spinal opioids can provide profound postoperative analgesia with fewer central and systemic adverse effects than with opioids administered systemically. ${ }^{2}$ Morphine and fentanyl have been used popularly. Sufentanil, the congener of fentanyl is 1000 more times potent than morphine is a newer addition to the armoury of modern day anaesthesiologists. The present study 
was done to assess the efficacy of sufentanil to reduce postoperative pain.

\section{MATERIALS AND METHODS. 3}

After approval of the Institutional Ethics Committee, a total of 100 patients undergoing elective perianal surgeries were included in the study and informed consent was obtained from either the patient or close relative before they were included in the study. The surgeries performed included haemorrhoidectomy, fistulectomy, maximal anal dilatation and lateral anal sphincterotomy. Patients in the age group of 20-60 with American Society of Anaesthesiologists Grade1 and 2 were included in the study. Patients with known allergy to lignocaine and sufentanil, coagulation abnormalities, ASA Grade 3 and 4, neurological or neuromuscular disease were excluded from the study. Patients unwilling to participate were excluded.

The study population of 100 patients were randomly divided into two groups of 50 each to receive the following treatments: $5 \%$ hyperbaric lignocaine $50 \mathrm{mg}$ in $1 \mathrm{~mL}$ (Group A) and 5\% hyperbaric lignocaine $50 \mathrm{mg}$ with sufentanil $10 \mu \mathrm{g}$ (Group B). All the drugs were administered intrathecally.

All patients were explained about the Visual Analog Scale (VAS) and standardized perioperative and anaesthetic procedures were followed. ${ }^{4}$ Intravenous access was obtained in the forearm with 18 gauge IV cannula and lactated ringer solution $500 \mathrm{~mL}$ was infused intravenously before the block. The monitors connected to the patient included non-invasive blood pressure monitor, oxygen saturation using pulse oximeter. Baseline readings of pulse, blood pressure, respiratory rate and $\mathrm{SPo} 2$ were recorded. Spinal anaesthesia was induced with a 27 gauge Whitacre needle in the L2-3 or L3-4 vertebral space. The standard IV fluid protocol was 20 $\mathrm{mL} / \mathrm{kg}$ of modified ringer lactate solution before the induction of spinal anaesthesia. A volume of $1 \mathrm{~L}$ of ringer lactate was given every 8-12 hours for 24 hours after surgery. Hypotension episodes where reduction of blood pressure greater than $20 \%$ was treated with mephentermine $6 \mathrm{mg}$ intravenous increments and bradycardia as pulse rate less than 60 treated by atropine $0.6 \mathrm{mg}$ intravenous stat.

\section{Assessment of Sensory Blockade}

The onset of sensory block was tested by pin prick method using a hypodermic needle. The time of onset was taken from time of injection of drug into subarachnoid space to loss of pin prick sensation. The highest level of sensory block and time required to achieve it was noted. The time for two dermatomal segment regression of sensory level was noted. Duration of sensory blockade was taken as time from onset to time of return of pin prick sensation to S1 dermatome.

\section{Assessment of Motor Blockade}

Motor blockade was assessed by Bromage scale. 5 The time interval between drug administrations into subarachnoid space to the patient's inability to lift the straight extended leg was taken as onset time. The time taken to complete regression of motor blockade from time of drug administration was taken as duration of motor blockade.

\section{Assessment of Analgesia}

Pain was assessed by visual analogue scale. The VAS which was explained to the patient preoperatively was used to assess the pain. In all the patients, intensity of pain and pain relief following injection of the drug was assessed by VAS (Pain score of $0-10 \mathrm{~cm}$, where $0 \mathrm{~cm}=$ no pain and $10 \mathrm{~cm}=$ worst pain possible). Pain was evaluated at $0,1,3,6,12,18$ and at 24 hours and onset of analgesia was noted.

\section{Time to Ambulation}

It is the difference between time of ambulation and time of intrathecal injection.

\section{STATISTICAL ANALYSIS}

All data analysis was completed using SPSS software. Data were expressed as mean \pm SD. Quantitative data was analysed using unpaired ' $\mathrm{t}$ ' test. Side effects were compared by Chisquare test. $\mathrm{P}<0.05$ was considered as statistically significant.

\section{RESULTS}

There was no statistically significant difference between the two groups with regard to age, sex, height and weight (Table 1). There was no variation with regard to the onset of sensory and motor blockade between the two groups (Table 2). The mean time to achieve peak sensory level was 2-3 minutes earlier and majority of patients in sufentanil group achieved higher sensory levels up to T6 level. The time for two segment regression and the time to full sensory and motor recovery was prolonged in sufentanil group. The mean duration of complete and effective analgesia in sufentanil group was significantly higher than lignocaine alone (Table 3-5). Also the time for ambulation is significantly lower in sufentanil group in comparison to lignocaine.

The cardiovascular profile was remarkably stable throughout the intraoperative period in both the groups. There was no significant difference in heart rate and no episodes of bradycardia occurred in either group. Changes in mean systolic blood pressure at any time interval were insignificant, both statistically and clinically. Changes in mean diastolic blood pressure were statistically significant at 20,30 and 60 minutes. However, the changes were clinically significant. The changes in cardiac parameters, i.e. heart rate and fall in systolic and diastolic blood pressure at any time interval were statistically and clinically insignificant. The incidence of hypotension was slightly higher in sufentanil group (12\%) when compared to lignocaine group (6\%).

Hypotension was easily corrected with small doses of mephentermine and ephedrine. Respiratory depression is one of the major side effects of intrathecal opioids. None of the patients in the study experienced respiratory depression and there was no significant difference in the mean respiratory rate between the two groups. The incidence of perioperative complications and side effects was similar in both the groups with the exception of pruritus slightly higher in sufentanil group (Table 6).

\begin{tabular}{|c|c|c|c|}
\hline Parameter & Group A & Group B & P Value \\
\hline Age (Years) & $43.12 \pm 10$ & $39.56 \pm 11.9$ & 0.12 \\
\hline Male:Female & $29: 21$ & $26: 24$ & 0.44 \\
\hline Height (Feet) & $5.42 \pm 0.32$ & $5.39 \pm 0.23$ & 0.590 \\
\hline Weight (kg) & $57.28 \pm 8.5$ & $57.8 \pm 8.051$ & 0.99 \\
\hline \multicolumn{4}{|c|}{ Table 1: Demographic Profile } \\
\hline
\end{tabular}




\begin{tabular}{|c|c|c|}
\hline Parameter & Sensory Block & Motor Block \\
\hline Group A (Lignocaine) & $135.49 \pm 13.3$ & $188 \pm 21.1$ \\
\hline $\begin{array}{c}\text { Group B } \\
\text { (Lignocaine+Sufentanil) }\end{array}$ & $135.12 \pm 7.5$ & $197 \pm 11.3$ \\
\hline $\mathrm{p}$ Value & 0.705 & 0.055 \\
\hline \multicolumn{3}{|c|}{ Table 2: Onset of Sensory and Motor Block } \\
\hline
\end{tabular}
Mean \pm SD

Onset expressed in seconds and values expressed as

\begin{tabular}{|c|c|}
\hline & $\begin{array}{c}\text { Time to Peak Sensory } \\
\text { Block }\end{array}$ \\
\hline Lignocaine group & $8.17 \pm 1.19$ \\
\hline $\begin{array}{c}\text { Lignocaine+Sufentanil } \\
\text { group }\end{array}$ & $6.38 \pm 1.8$ \\
\hline \multicolumn{2}{|c|}{ Table 3: Onset of Peak Sensory Block } \\
\hline
\end{tabular}

Time expressed in minutes and values expressed as Mean \pm SD.

\begin{tabular}{|c|c|c|c|}
\hline Parameter & $\begin{array}{c}\text { Lignocaine } \\
\text { Group }\end{array}$ & $\begin{array}{c}\text { Lignocaine }+ \\
\text { Sufentanil }\end{array}$ & $\begin{array}{c}\mathbf{p} \\
\text { value }\end{array}$ \\
\hline $\begin{array}{c}\text { Duration of } \\
\text { complete } \\
\text { analgesia }\end{array}$ & $66.04 \pm 33.2$ & $80.8 \pm 18.8$ & $<0.01$ \\
\hline $\begin{array}{c}\text { Duration of } \\
\text { effective } \\
\text { analgesia }\end{array}$ & $81.1 \pm 30.1$ & $109.1 \pm 22.9$ & $<0.01$ \\
\hline $\begin{array}{c}\text { Time to first } \\
\text { pain } \\
\text { medication }\end{array}$ & $104.71 \pm 23.8$ & $120.86 \pm 24.4$ & $<0.01$ \\
\hline \multicolumn{3}{|c|}{ Table 4: Duration of Analgesia } \\
\hline
\end{tabular}

\begin{tabular}{|c|c|c|c|}
\hline Parameter & $\begin{array}{c}\text { Lignocaine } \\
\text { Group }\end{array}$ & $\begin{array}{c}\text { Lignocaine } \\
\text { +Sufentanil } \\
\text { Group }\end{array}$ & $\begin{array}{c}\mathbf{p} \\
\text { value }\end{array}$ \\
\hline $\begin{array}{c}\text { Time to } 2 \\
\text { segment } \\
\text { regression }\end{array}$ & $51.79 \pm 17.9$ & $75.5 \pm 14.2$ & $<0.01$ \\
\hline $\begin{array}{c}\text { Time to } \\
\text { complete } \\
\text { sensory } \\
\text { recovery }\end{array}$ & $111.4 \pm 14$ & $126.4 \pm 13$ & $<0.01$ \\
\hline $\begin{array}{c}\text { Time to motor } \\
\text { recovery }\end{array}$ & $99.7 \pm 13$ & $104.5 \pm 12.9$ & $<0.01$ \\
\hline $\begin{array}{c}\text { Time to } \\
\text { ambulation }\end{array}$ & $160 \pm 26$ & $129 \pm 24$ & $<0.01$ \\
\hline \multicolumn{4}{|c|}{ Table 5: Recovery Parameters } \\
\hline \multicolumn{4}{|c|}{} \\
\hline
\end{tabular}

\begin{tabular}{|c|c|c|c|}
\hline $\begin{array}{l}\text { Adverse } \\
\text { Effects }\end{array}$ & $\begin{array}{l}\text { Lignocaine } \\
\text { Group (\%) }\end{array}$ & $\begin{array}{c}\text { Lignocaine + } \\
\text { Sufentanil } \\
\text { Group (\%) }\end{array}$ & $\begin{array}{c}p \\
\text { value }\end{array}$ \\
\hline Nausea/Vomiting & 8 & 12 & $>0.05$ \\
\hline Pruritus & 0 & 15 & $<0.05$ \\
\hline Shivering & 8 & 0 & $<0.05$ \\
\hline Bradycardia & 0 & 0 & $>0.05$ \\
\hline Hypotension & 8 & 6 & $>0.05$ \\
\hline Drowsiness & 4 & 4 & $>0.05$ \\
\hline \multicolumn{4}{|c|}{ Table 6: Perioperative Complications } \\
\hline
\end{tabular}

\section{DISCUSSION}

Spinal anaesthesia with hyperbaric lignocaine 5\%, a popular method used safely and successfully for almost 100 years has many potential advantages over general anaesthesia, especially for operations involving over abdomen, perineum and the lower extremities. The duration of spinal analgesia can be prolonged by adjuvants like vasoconstrictors, opioids, neostigmine, ketamine, midazolam, etc. Vasoconstrictors prolong the duration of action of local anaesthetic by decreasing systemic absorption, but has been found to induce neurological signs and symptoms due to reduced blood supply to the spinal cord. Intrathecal midazolam produces sedation, ketamine results in psychomotor symptoms and neostigmine causes excessive nausea and vomiting. ${ }^{6}$

In the context of augmentation strategies, intrathecal opioid administration is a significant advancement in pain management. Studies have shown that spinal opioids can provide profound postoperative analgesia with fewer central and systemic adverse effects than with opioids administered systemically. Combination of opioids and their derivatives provides better relief from pain, early recovery and reduction in adverse effects. ${ }^{7}$ Morphine and fentanyl have been used popularly. Sufentanil, the congener of fentanyl is 1000 more times potent than morphine is a newer addition to the armoury of modern day anaesthesiologists. The present study was done to assess the efficacy of sufentanil to reduce postoperative pain in perianal surgeries.

Comparison of our results and those in the literature suggest that combination of sufentanil and lignocaine improves analgesia from that of lignocaine given alone. Patients who received a combination of sufentanil and lignocaine had lower pain scores than those who received lignocaine alone.

The duration of complete analgesia in sufentanil group was prolonged by 15 to 20 minutes and the duration of effective analgesia was prolonged by 30 to 40 minutes (Fig. 1). The time to first request of analgesics was prolonged by 20 minutes. There was significant reduction in the VAS scores in sufentanil group in the first six hours postoperatively and the need of analgesics was reduced. Similar observations were made by SK Ngiam et al. and Dahlgren et al. with the use of Sufentanil and Fentanyl and there was no need of additional intraoperative analgesics in comparison to bupivacaine alone and placebo group. 8,9

Waxler et al. reported shorter time to ambulation in patients who received intrathecal lignocaine and sufentanil. ${ }^{10}$ Lau et al. also reported earlier discharge of outpatients on lignocaine and sufentanil who underwent extracorporeal shock wave lithotripsy. ${ }^{11}$ Similar results were observed in our study with significant decrease in ambulation time. However, time to complete sensory and motor recovery were prolonged in sufentanil group.

The cardiovascular profile was remarkably stable throughout the intraoperative period in both the groups. There were no episodes of bradycardia in either group. There were no changes in systolic blood pressure and there was no significant difference in haemodynamic parameters in both the groups. Similar results were observed by SK Ngiam et al. and whereas Asehnoune $\mathrm{K}$ et al. reported better cardiac stability with combination of sufentanil and lignocaine. ${ }^{8}$ Hong $\mathrm{JY}$ et al. reported the combination of epidural ropivacaine and sufentanil was associated with the most pronounced 
attenuation of the stress response. ${ }^{12}$ Ben David et al. ${ }^{13}$ reported reduced incidence of Transient Neurological Symptoms (TNS) and faster recovery with lignocaine and fentanyl than lignocaine alone.

Side effects observed include pruritus (30\%), nausea and vomiting (12\%) and drowsiness (8\%) in sufentanil group. Lignocaine group patients had shivering (8\%), nausea and vomiting $(8 \%)$. The side effect incidence was similar in both the groups. Incidence of urinary retention is known to be higher with the use of intrathecal opioids. None of the patients in our study had urinary retention. Beverly Waxleretal reported itching as a well-known side effect of intrathecal narcotics. ${ }^{10}$ Incidence of pruritus was $56 \%$ with sufentanil and lignocaine in their study. No respiratory depression was observed. Other studies have reported such complications in special populations like pregnancy and elderly patients.

Vyas et al.14 reported higher incidence of pruritus with sufentanil $7.5 \mu \mathrm{g}$. SK Ngiam et al. reported incidence of pruritus as $35 \%$ with Sufentanil and $27.8 \%$ with fentanyl as against $0 \%$ with lignocaine alone. Dunn SM et al. reported higher incidence of itching with intrathecal sufentanil when compared to epidural sufentanil. ${ }^{6}$ Facial pruritus associated with spinal opiate analgesia in man is thought to result either from release of histamine or from imbalance of sensory modulation secondary to spread of opiate to the medulla or fourth ventricle. 15

\section{SUMMARY AND CONCLUSION}

With the present study, we can summarize that addition of sufentanil to hyperbaric lignocaine in spinal anaesthesia significantly increased the duration and quality of analgesia and thus reducing the analgesic requirement in the early postoperative period ( 4 to 6 hours). The duration of sensory and motor blockade was prolonged and higher levels of sensory blockade were achieved. We conclude combination of sufentanil and lignocaine is a better option to relieve pain effectively and also promotes faster recovery.

\section{REFERENCES}

1. Parameshwara G. Spinal, epidural to combined spinal epidural analgesia, the history of central neuraxial block. Indian J Anaesth 2001;45(6):406-12.

2. Saxena AK, Arava SK. Current concepts in neuraxial administration of opioids and non-opioids: an overview and future perspectives. Indian $\mathrm{J}$ Anaesthesia 2004;48(1):13-24.
3. Campbell DC, Camann WR, Datta S. The addition of bupiva-caine to intrathecal sufentanil for labor analgesia. Anesth Analg 1995;81(2):305-9.

4. Myles PS, Troedel S, Boquest M, et al. The pain visual analog scale: is it linear or nonlinear? Anesth Analg 1999;89(6):1517-20.

5. Bromage PR, ed. Epidural analgesia. Philadelphia: WB Saunders, 1978;176-214.

6. Dunn SM, Connelly NR, Steinberg RB, et al. Intrathecal sufentanil versus epidural lidocaine with epinephrine and sufentanil for early labor analgesia. Anesth Analg 1998;87(2):331-5.

7. Shareef SM, Sridhar I, Dakshayani KM, et al. Evaluation of the effects of tramadol and diclofenac alone and in combination on post cesarean pain. Int J Basic Clin Pharmacol 2014;3(3):470-3.

8. Ngiam SK, Chong JL. The addition of intrathecal sufentanil and fentanyl to bupivacaine for caesarean section. Singapore Med J 1998;39(7):290-4.

9. Gunnar Dahlgren, Christer Hultstrand, Jan Jakobsson, et al. Eriksson and helena m Intrathecal sufentanil, fentanyl, or placebo added to bupivacaine for cesarean section. Anesth Analg 1997;85:1288-93.

10. Beverly Waxler, Shirley A Mondragon, Sonal N Patel, et al. Intrathecal lidocaine and sufentanil shorten postoperative recovery after outpatient rectal surgery. Anadian journal of anaesthesia 2004;51(7):680-4.

11. Lau WC, Green CR, Faerber GJ, et al. Intrathecal sufentanil for extracorporeal shock wave lithotripsy provides earlier discharge of the outpatient than Intrathecal lidocaine. Anesth Analg 1997;84(6):1227-31.

12. Hong JY, Yang SC, Yi J, et al. Epidural ropivacaine and sufentanil and the perioperative stress response after a radical retro pubic prostatectomy. Acta Anaesthesiologica Scandinavica 2011;55(3):282-9.

13. Ben-David B, Solomon E, Levin $\mathrm{H}$, et al. Intrathecal fentanyl with small-dose dilute bupivacaine: better anesthesia without prolonging recovery. Anesth Analg 1997;85(3):560-5.

14. Vyas N, Sahu DK, Parampill R. Comparative study of intrathecal sufentanil bupivacaine versus intrathecal bupivacaine in patients undergoing elective cesarean section. Journal of Anaesthesiol Clinical Pharmacol 2010;26(4):488-92.

15. Peter V Scott, Fischer HBJ. Spinal opiate analgesia and facial pruritus: a neural theory. Postgrad Med J 1982;58(683):531-5. 